\title{
AUTOBIOGRAFSKA MEMORIJA I ERIKSONOVI STADIJUMI PSIHOSOCIJALNOG RAZVOJA
}

\section{Ljiljana Mihić', Kristina Krstić i Ivana Ignjatović}

Odsek za psihologiju, Filozofski fakultet, Novi Sad

Prikazano istraživanje je usmereno na proučavanje 1) autobiografskih memorija starih osoba u kontekstu Eriksonovih psihosocijalnih stadijuma razvoja, 2) emocionalnog tona autobiografskih memorija kao i 3) fenomena kod odraslih osoba koji ukazuje da najveći broj autobiografskih memorija potiče iz perioda između 20. i 30. godine života (efekta reminiscencije). Uzorak je činilo 65 ispitanika, prosečne starosti 69 godina, sa različitih podneblja Republike Srbije. Putem intervjua evocirali su 1265 pojedinačnih događaja iz svog dosadašnjeg iskustva. Za analizu podataka korišćena je deskriptivna statistika, poređenje distribucija i analiza korespondencije. Rezultati istraživanja su bili u skladu sa sledećim pretpostavkama: a) najdostupnija autobiografska sećanja evocirana u okviru tačno određenih životnih dekada, s obzirom na razvojno relevantne zadatke, korespondiraju sa Eriksonovim stadijumima psihosocijalnog razvoja, b) najveći broj evociranih uspomena je pozitivnog emocionalnog tona, $i$ c) efekat reminiscencije se javlja samo kod memorija pozitivnog emocionalnog tona. Rezultati su diskutovani u svetlu teorije self-memorija sistem.

Ključne reči: autobiografska memorija, razvojni stadijumi, emocionalni ton, efekat reminiscencije, Erikson

\footnotetext{
${ }^{1}$ lmihic@ff.uns.ac.rs
} 


\section{Uvod}

\section{Autobiografska memorija i self}

Autobiografska memorija se može definisati kao vrsta epizodičke memorije za retrospektivne i prospektivne informacije koje čine sastavni deo selfa (Schroots, Van Dijkum, \& Assink, 2004). U epizodičkoj memoriji su uskladištena naša sećanja i lična iskustva, odnosno sadržaj epizodičke memorije čine sećanja na događaje u kojima smo učestvovali, osobe koje poznajemo ili smo poznavali, mesta na kojima smo bili, stvari i predmeti koje smo koristili (Kostić, 2006). U pitanju su sadržaji čije je usvajanje moguće locirati u vremenu i prostoru i koji se odnose na lično iskustvo. U prilog epizodičkim autobiografskim sećanjima govore i istraživači koji su pokušali da identifikuju semantičku kategoriju autobiografskih sećanja. Piolino i saradnici su primetili da epizodičke instance autobiografskih sećanja sadrže memorije koje se tiču specifičnih događaja iz života pojedinca, na primer, diplomiranje, dok semantičke instance autobigrafskih sećanja sadrže generalne informacije o prošlosti pojedinca, na primer, prijatelji sa fakulteta (Piolino, Desgranges, Benali, \& Eustache, 2002)

Brojni istraživači su zapazili da postoje bliske veze između memorije i selfa. Na primer, Brewer (1986) je istakao da je upravo ta veza differentia specifica autobiografske memorije $u$ odnosu na ostale forme dugoročno-uskladištenih informacija. Priroda ove veze je posebno razmatrana u okviru tzv. teorije selfmemorija sistem (SMS; Conway \& Pleydall-Pearce, 2000; Conway \& Holms, 2004). Prema autorima teorije, self, koji se konceptualizije kao skup trenutnoaktuelnih životnih ciljeva i zadataka, određuje način na koji je znanje o sebi uskladišteno u memoriji kao i njegovu dostupnost (Conway \& Pleydall-Pearce, 2000; Conway \& Holms, 2004). Mada se razvojni zadaci selfa menjaju tokom života, predstavljajući proces koji se odvija tokom vremena, oni ostavljaju za osobom klastere visoko dostupnih sećanja koje su nekada bile za osobu visoko relevantni ciljevi. Moguće je da u sadašnjosti ovi klasteri self-determinišućih memorija (Singer \& Salovey, 1993, prema Conway \& Holmes, 2004) ne budu relevantni sa aspekta aktuelnih ciljeva, međutim, oni "grade“ self kroz konfiguraciju nekih prošlih ciljeva i na taj način obezbeđuju ličnu, psihološku istoriju selfa.

Pošavši od pretpostavke da ciljevi, odnosno razvojni zadaci, koji su aktuelni u određenom životnom periodu, predstavljaju najdostupnija sećanja iz svakog životnog perioda, Conway i Holms su sproveli istraživanje na uzorku starih ispitanika koristeći tehniku slobodnog prisećanja (Conway \& Holms, 2004). Najdostupnija sećanja su bila definisana kao prvih nekoliko uspomena koje su 
dobijene na zadatku slobodnog prisećanja, pri čemu je prisećanje bilo vremenski ograničeno na 5 minuta. Conway i Holms su zaključili da su najdostupnije bile one uspomene koje su se ticale važnih životnih zadataka, pri čemu su se životni zadaci uklapali u Eriksonovu teoriju o osam stadijuma psihosocijalnog razvoja (2004). Naime, iako je bilo sećanja koja nisu mogla biti klasifikovana s obzirom na razvojne zadatke, velika većina sećanja je mogla biti klasifikovana u sledećih osam stadijuma: sticanje poverenja, sticanje autonomije, sticanja inicijative, usvajanja odgovornosti, formiranja identiteta, intimnost, stvaralaštvo (generativnost) i integritet.

Prema Eriksonovoj teoriji, prvi stadijum koji se odvija tokom prve godine života obeležen je sticanjem poverenja nasuprot nepoverenja. Drugi stadijum obeležava razvoj autonomije nasuprot stida i sumnje. Karakteriše ga usvajanje znanja o obavezama i privilegijama i odvija se tokom druge i treće godine. Treći stadijum se vezuje za predškolski uzrast i odnosi se na razvoj inicijative naspram krivice. Polazak u školu označava početak četvrtog stadijuma razvoja kada je glavni razvojni konflikt vezan za pitanje usvajanje odgovornosti nasuprot osećanja manje vrednosti. Stupanjem u pubertet i tokom čitavog perioda mladalaštva odvija se stadijum razvoja identiteta naspram zbrke identiteta. Uspešno razrešenje krize ovog perioda dovodi do toga da je mlad čovek u stanju da preuzme odgovornost za svoje životne odluke i budućnost. To je period burnih promena čije je uspešno razrešenje krunisano razvojem identiteta, samostalnosti i samokontrole. Sledeći stadijum razvoja, nazvan intimnost naspram izdvojenosti, karakterišu zadaci pronalaženja stalnog partnera i zasnivanje sopstvene porodice. Stvaranje (generativnost) naspram zastoja je stadijum koji po Eriksonovoj teoriji zauzima najveći deo vremena u životnom ciklusu osobe. Odvija se tokom srednjeg životnog doba i karakterišu ga razvojni zadaci kao što su stvaranje porodice, briga o potomstvu i karijeri i prenos vrednosti na nove generacije. Integritet nasuprot očajanja je stadijum u životnom ciklusu koji započinje završetkom profesionalne karijere. Osoba koja je uspešno razrešila prethodne razvojne zadatke ulazi u ovaj stadijum sa velikim potencijalom da uspešno razreši novu razvojnu krizu. Naime, osoba stiče uverenje da je njen/njegov život imao smisla i da je pređeni životni put bio jedinstven i neponovljiv. Ovakvo uverenje je praćeno stavom tolerancije i uvažavanjem razlika u životnim putevima drugih ljudi (Jerković i Zotović, 2005). Deveti stadijum koji je posthumno dodat klasifikaciji je nazvan završen životni ciklus ili gerotranscendentalnost (Brown \& Lowis, 2003). Započinje u poznim osamdestim godina kada se osobe suočavaju sa gubitkom autonomije i problemima nepoverenja u svoje sposobnosti koje su počele da propadaju. Glavna razvojna kriza u ovim poznim godinama tiče se gubitka autonomije, snage i osećaja kontrole nad životom, čije se razrešenje postiže napuštanjem 
materijalitičkog viđenja sveta i okretanjem transcendentalnoj životnoj sferi. Veruje se da osobe, nakon razrešenja krize u ovom poslednjem životnom stadijumu, shvataju da je njihov život deo šire, kosmičke dimenzije, preferiraju samoću tokom koje se posvećuju spokojnom razmišljanju, izbegavaju neautentične ljudske relacije, manje su zainteresovane za materijalna dobra, što je sve praćeno povećanjem životnog zadovoljstva (Tornstam, 1992).

Istraživanje prikazano $\mathrm{u}$ ovom radu je delimično inspirisano nalazima Conwaya i Holmsa kao i SMS teorijom po kojoj su najdostupnija sećanja ona koja se tiču važnih životnih problema, odnosno razvojnih zadataka, postavljenih ciljeva ili stremljenja iz određenog životnog razdoblja. Kao jedan istraživački cilj, proveravana je generabilnost rezultata koji su dobijeni na engleskom govornom području pri čemu su se testirale sledeće hipoteze: a) najdostupnija sećanja evocirana u okviru tačno određenih životnih dekada, putem razvojno relevantnih zadataka osobe, korespondiraju sa Eriksonovim stadijumima psihosocijalnog razvoja, i b) razvojni zadaci pojedinih psiho-socijalnih stadijuma protežu se tokom većeg broja životnih dekada dok pojedini psiho-socijalni stadijumi jasnije korespondiraju sa određenom životnom dekadom. To se posebno odnosi na period generativnosti koji, po Eriksonu, treba da obuhvata veliki deo srednjeg odraslog doba (Conway \& Holms, 2004). Dakle, distribucija sećanja koja su klasifikovana kao generativna bi trebalo da je zatupljenija u odnosu na ostale psihosocijalne stadijume. Novina u odnosu na ranija istraživanja u ovoj oblasti se ogleda $u$ diferenciranijem prikazu razvojnih zadataka $u$ poznoj starosti (80 godina i naviše) a u svetlu posthumnog razvoja Eriksonove teorije.

\section{Autobiografska memorija, self i efekat reminiscencije}

Pored testiranja hipoteze o najdostupnijim autobiografskim memorijama, ovo istraživanje je imalo za drugi cilj proučavanje distribucija retrospektivnih sećanja sa akcentom na zasebne distribucije za pozitivne i negativne životne događaje tokom životnih dekada kod starih osoba. Relativno robustan nalaz je da frekvencije sećanja na događaje tokom životnog ciklusa kod odraslih ispitanika (preko 35 godina) formiraju bimodalnu distribuciju (na primer Rubin, Rahhal \& Poon, 1998; Martin \& Smyer, 1990). Dakle, najviše detalja se pamti iz ranog zrelog perioda (između dvadesete i tridesete godine), nakon čega slede događaji iz neposredne prošlosti, dok se događaji iz zrelog perioda relativno slabo pamte. Prvi i najviši vrh koji odgovara životnim periodu između 20 i 30 godina života je nazvan efekat reminiscencije (reminiscence bump), dok je drugi nešto niži vrh na distribuciji frekvencija sećanja nazvan efekat skorašnjosti (Conway \& Pleydell-Pearce, 2000; Rubin, 2002, prema 
Schroots et al., 2004). U novijim istraživanjima je utvrđeno da se efekat reminiscencije javlja samo za pozitivne događaje ali ne i za negativne i traumatske događaje (Bernsten \& Rubin, 2002; Gluck \& Bluck, 2007).

U smislu objašnjenja ovog bimodalnog obrasca predlagane su brojne interpretacije kao što su kognitivne, neuralne, genetske i razvojno-formativne (Schroots et al., 2004). U svetlu naše prethodne diskusije o važnosti veza između dva sistema, memorije i selfa, nešto detaljnije ćemo predstaviti objašnjenja sa aspekta formiranja identiteta. Prema Eriksonovoj teoriji, identitet osobe počinje da se uobličava tokom kasne adolescencije i ranog odraslog doba. Dakle, mnogi događaji iz ovog perioda će biti bolje zapamćeni jer su u vezi sa formiranjem novog identiteta osobe. Sećanja iz ovog perioda verovatno će biti organizovana i integrisana u celokupnu priču ili viđenje selfa, te otuda sledi njihova prednost prilikom prisećanja (Rathbone, Moulin, \& Conway, 2008). U prilog ove teze idu i noviji podaci koji pokazuju da kod osoba koje su doživele značajne životne promene u kasnijim životnim periodima (na primer emigriranje) ne pokazuju bimodalnu distribuciju sećanja već se pojavljuje novi šiljci na distribuciji sećanja koji odgovaraju vremenu emigriranja, i verovatno, formiranju novog selfa (Conway \& Haque, 1999).

Conway \& Holms (2004) su takođe pronašli postojanje efekta reminiscencije. Međutim, autori su posmatrali distribucije svih sećanja nezavisno od njihovog afektivnog tona ostavljajući otvoreno pitanje da li je efekat proizveden usled boljeg prisećanja samo pozitivnih sećanja, što nam sugerišu noviji nalazi. Dakle, u skladu sa novijim saznanjima iz ove oblasti, pretpostavljamo da će se efekat reminiscencije očitovati samo među najdostupnijim sećanjima pozitivnog afektivnog tona.

\section{Emocionalni ton autobiografskih memorija i starenje}

Istraživači koji se bave proučavanjem emocionalnog tona autobiografskih memorija zaključuju da ljudi generalno teže da događaje u autobiografskoj memoriji percipiraju kao pozitivne i prijatne. Rezimirajući objavljene studije koje su se bavile emocionalnim tonom autobiografskih sećanja, Walker i saradnici su naveli da se približno $50 \%$ životnih događaja procenjuje u pozitivnom svetlu dok se približno 25\% događaja procenjeno kao negativno (Walker, Skowronski, \& Thompson, 2003). Drugi podatak koji sugeriše postojanje pristrasnosti prema pozitivnom $u$ autobiografskim sećanjima tiče se brzine kojom bledi intenzitet pozitivnih i negativnih emocija. Afektivna obojenost događaja iščezava sa protokom vremena pri čemu je ovaj efekat naročito postojan za sećanja na negativne događaje. Pad u intenzitetu je strmiji za sećanja na nega- 
tivne nego na pozitivne događaje (Walker, Vogl, \& Thompson, 1997). Tvrdnja o postojanju pozitivne pristrasnosti u autobiografskoj memoriji je potkrepljena činjenicom da su slični rezultati dobijeni ne samo u retrospektivnim studijama već i u dnevničkim praćenjima kao i eksperimentima (Thompson, Skowronski, Larsen, \& Betz, 1996; Kennedy, Mather, \& Carstensen, 2004). Naravno, postoje i stanja, kao što su prisustvo disforije ili depresivnog afekta, koja dovede do toga da se gore-navedeni efekti gube (Seidlitz, Wyer, \& Diener, 1997; Walker, Skowronski, Gibbson, Vogl, \& Thompson, 2003).

Pozitivna pristrasnost $\mathrm{u}$ autobiografskim memorijama je uočena i kod stare populacije. U nekoliko longitudinalnih studija je ustanovljeno da prilikom rekonstrukcije događaja iz prošlosti stariji ispitanici, u poređenju sa mlađim, teže da događaje vide u pozitivnijem svetlu u odnosu na vreme kada su se događaji zbili (na primer, Wagenaar \& Groeneweg, 1990). Prevazilazeći nedostatke longitudinalnih studije (recimo kao što je korišćenje različitih upitnika tokom istraživanja), Kennedy i saradnici eksperimentalnim putem dolaze do sličnih rezultata (Kennedy et al., 2004). Naime, stariji ispitanici, od kojih je traženo da se prisete ličnih informacija o kojima su izvestili pre 14 godina a koji su bili dostupni istraživačima, su manifestovali pozitivnu pristrasnost. Pristrasnost je registrovana u dve situacije: prilikom neutralne instrukcije koja je zahtevala od ispitanika da se samo prisete informacija i eksperimentalnog uslova koji je zahtevao da se prilikom prisećanja pažnja usmeri na trenutna osećanja. Kod obe grupe, raspoloženje ispitanika se poboljšalo nakon prisećanja, što je poslužilo kao argument istraživačima da je pozitivna pristrasnost u autobiografskim sećanjima u funkciji regulacije emocija. Postojao i dodatni eksperimentalni uslov koji je zahtevao od starih ispitanika da se prisete informacija sa ciljem da prisećanje bude što tačnije. U situaciji kada je prisećanje bilo rukovođeno zahtevom za tačnošću, nije došlo ni do pozitivne pristrasnosti u sećanjima niti do poboljšanja raspoloženja.

Različita objašnjenja motivacione prirode su ponuđena kako bi se objasnila pozitivna pristrasnosti prilikom rekonstrukcije memorija. Na primer, rezultat koji je replikovan u brojnim kros-kulturnim istraživanjima u društvima koje su iznad praga siromaštva je da većina ljudi izveštava da je zadovoljna svojim životom (Walker et al., 2003). Pretpostavlja se je pozitivna pristrasnost autobiografskih memorija u službi održavanja doživljenog zadovoljstva sopstvenim životom (Walker et al., 2003). Nešto specifičnija teorija koja je nastala sa ciljem objašnjenja pozitivne pristrasnosti autobiografskih memorija kod starih osoba je Karstensenova teorija socioemocionalnog selektiviteta (Carstensen, Isaacowitz, \& Charles, 1999). Prema ovoj teoriji, predstava o ograničenom vremenu koje preostaje dovodi do toga da su starije osoba u poređenju sa 
mlađim osobama motivisanije da maksimiziraju pozitivan afekat i minimiziraju negativan, pri čemu im u tome im pomažu sledeće strategije regulacije emocija: opažanje životnih izbora u pozitivnijem svetlu, izbegavanje usmeravanja pažnje na negativne informacije, lošije pamćenje negativnih vizuelnih informacija u odnosu na pozitivne, opažanje prošlih negativnih događaja kao manje intenzivnih $u$ odnosu na intenzitet $u$ vreme stvarnog dešavanja, kao i provođenje vremena sa selekcioniranim, manjim brojem bliskih prijatelja (Carstensen, 1991; Charls, Mather, \& Carstensen, 2003; Mather \& Carstensen, 2003; Levine \& Bluck, 1997).

$\mathrm{Na}$ osnovu ovog kratkog pregleda literature dobijenoj i na opštoj i na staroj populaciji, pretpostavljamo da će tokom retrospektivnih rekonstrukcija sećanja $u$ različitim životnim dekadama dominirati pozitivan afektivni ton u poređenju sa negativnim. Budući da je većina istraživanja u ovoj oblasti obavljena u zemljama koja su po ekonomskim, kulturološkim i socijalnim odlikama bitno drugačija u odnosu na naše uslove, važno je ustanoviti da li postoji tendencija pozitivne pristrasnosti autobiografskim sećanja i kod naših ispitanika starosti preko 65 godina života.

\section{Metod}

\section{Ispitanici}

Uzorak su činile osobe sa različitih podneblja Republike Srbije, mada pretežno sa područja Vojvodine. U ovom terenskom istraživanju, tokom maja 2008. godine, intervjuisano je 65 ispitanika. Prosečna starost je bila 69 godina.

\section{Procedura}

Ispitanici su imali zadatak da evociraju sećanja iz različitih životnih dekada. Tokom intervjua istraživač je zadavao dekade u okviru kojih je ispitanik trebalo da se priseća događaja iz svog života. Ukupan broj zadatih dekada varirao je u zavisnosti od godina ispitanika (na primer, 0-9, 10-19, 20-29, 3039, 40-49, 50-59, 60 godina i naviše). Kako ispitanici ne bi usvojili određenu strategiju pretraživanja sećanja (na primer, pretraživanje u skladu sa opaženim očekivanjem istraživača) ispitanici su dobili neutralnu instrukciju da opišu događaje koji im prvi padnu na pamet (Conway \& Holmes, 2004). U cilju dolaženja do najpristupačnijih sećanja, vreme prisećanja događaja za svaku pojedinačnu životnu dekadu je iznosilo oko pet minuta, pri čemu je broj sećanja bio ograničen na tri. Pored konkretnog događaja za istraživanje su bili re- 
levantni i detalji kao što su: mesto odvijanja, aktuelne godine, osobe uključene u uspomene, i osećanja. Nakon četiri minuta intervjuer bi zamolio ispitanika da priču o događaju privede kraju i da se pripremi za narednu dekadu. Učesnici su bili ispitivani individualno, posredstvom više nezavisnih intervjuera.

Ograničenja koja su poštovana prilikom istraživanja (3 događaja unutar 5 minuta), su postavljena na osnovu preporuke da se maksimalna efikasnost u prisećanju i opisivanju događaja kod ove uzrasne grupe postiže unutar ovih parametara (Conway \& Holmes, 2004). Takođe, pretpostavlja se da prva tri sećanja koja se prizvana na ovaj način predstavljaju sećanja koja bi trebalo da definišu self (Rathbone et al., 2008)

\section{Kodiranje sećanja}

Kodiranje s obzirom na psihosocijalne stadijume razvoja. Sećanja su kodirana u skladu sa Eriksonovim psihosocijalnim stadijumima, pri čemu se prva četiri odvijaju u detinjstvu, peti u mladalaštvu, a sledeća tri tokom odraslog doba (Jerković i Zotović, 2005). U svetlu posthumnog razvoja Eriksonove teorije, razmatran je i deveti stadijum nazvan završen životni ciklus. S obzirom na to da prva četiri stadijuma obuhvataju samo kratak period života, oni su u ovom istraživanju obuhvaćeni nadređenim, širim stadijumom - detinjstvo. Time je ovaj zbirni stadijum bio izjednačen sa ostalim stadijumima po dužini kao i po broju evociranih sećanja.

Sećanja za koja je utvrđeno da sadrže karakteristike iz samo jednog stadijuma, odnosno da se odnose na razvojne zadatke iz konkretnog perioda, klasifikovana su kao sećanja iz tog stadijuma. Sećanja koja nisu mogla biti jasno povezana sa pojedinačnim psihosocijalnim periodom, kao i ona koja su se odnosila na veoma teška životna događanja, uglavnom gubitke, su određena kao neklasifikovana. Dva nezavisna procenjivača su kodirala sećanja, a dobijeni stepen slaganja pri klasifikaciji je bio izuzetno visok i iznosio je kappa $=0.94$.

Klasifikacija s obzirom na emocionalni ton. Emotivni ton evociranih sećanja je procenjen korišćenjem petostepene skale od -2 do +2 . Ton je operacionalizovan na sledeći način: pozitivan (ako je na skali ocenjen kao +1 ili +2 ), negativan (ako je na skali ocenjen kao -2 ili -1), ambivalentan (ako je na skali ocenjen kao $-1 \mathrm{i}+1 \mathrm{tj}$. ukoliko sadrži i pozitivan i negativan kvalitet) i neutralan (ako je ocenjen kao 0). Stepen slaganja između dva procenjivača s obzirom na emocionalni ton je takođe bio izuzetno visok i iznosio je kappa $=0.96$. 


\section{Analiza podataka}

U cilju proveravanja hipoteze da će najdostupnije memorije iz različitih životnih perioda korespondirati sa važnim životnim zadacima prikazane su frekvencije i distribucije sećanja prema životnim dekadama i psihosocijalnim stadijumima. Za analizu emocionalnog tona sećanja prema životnim dekadama korišćene su analize distribucija (hi-kvadrat i Cramer's $V$ ) i dva Friedmanova testa. Prilikom računanja Friedmanovih testova, dekade su predstavljale faktor sa ponovljenim merenjem, dok su broj sećanja sa pozitivnim i negativnim emocionalnim tonom činili zavisne varijable. Friedmanovim testovima je bilo obuhvaćeno prvih sedam životnih dekada kako bi se izbegla poređenja sa kasnijim dekadama za koje je bio vezan relativno mali broj autobigrafskih memorija. Kako bi se ispitalo da li se efekat reminiscencije pojavljuje samo kod najpristupačnijih sećanja pozitivnog afektivnog tona, distribucije pozitivnih i negativnih memorija kroz životne dekade su poređene sa uniformnom distribucijom. Takođe, urađena je i analiza korespondencije. Kod analize korespondencije, životne dekade i emocionalni ton su predstavljale dve ulazne, kategorijalne varijable.

\section{Rezultati}

Ispitanici su evocirali ukupno 1265 pojedinačnih događaja iz svog dosadašnjeg iskustva.

U Tabeli 1 su prikazane frekvencije sećanja prema životnim dekadama i psihosocijalnim stadijumima.

Tabela 1. Broj autobiografskih sećanja kroz dekade i stadijume

\begin{tabular}{lrrrrrrrrrr}
\hline $\begin{array}{l}\text { Psihosocijal- } \\
\text { ni stadijumi }\end{array}$ & $0-9$ & $10-19$ & $20-29$ & $30-39$ & $40-49$ & $50-59$ & $60-69$ & $70-79$ & $80+$ & Ukupno \\
\hline Detinjstvo & 145 & 16 & 0 & 0 & 0 & 0 & 0 & 0 & 0 & 161 \\
Identitet & 2 & 98 & 20 & 0 & 1 & 0 & 0 & 0 & 0 & 121 \\
Intimnost & 0 & 37 & 71 & 25 & 11 & 3 & 2 & 0 & 0 & 149 \\
Generativnost & 0 & 10 & 87 & 135 & 122 & 92 & 44 & 9 & 3 & 502 \\
Integritet & 0 & 0 & 0 & 0 & 13 & 43 & 51 & 20 & 2 & 129 \\
Životni ciklus & 0 & 0 & 0 & 0 & 0 & 2 & 3 & 2 & 3 & 10 \\
Neklasifikov. & 39 & 32 & 16 & 20 & 30 & 28 & 23 & 5 & 0 & 193 \\
Ukupno & 186 & 193 & 194 & 180 & 177 & 168 & 123 & 36 & 8 & 1265 \\
\hline
\end{tabular}


Većina memorija (78\%) iz 0-9 dekade su bile klasifikovane kao memorije koje pripadaju prvom Eriksonovom psiho-socijalnom stadijuma tj. detinjstvu. Slično, nešto više od polovine memorija (51\%) iz 10-19 dekade se ticala razvojnih problema formiranja identiteta tj. drugog Eriksonovog psiho-socijalnog stadijuma. Iz iste dekade, znatno manji procenat (19\%) je reflektovao psihosocijalne zadatke uspostavljanja afektivnih veza i intimnosti. Međutim, ako se posmatraju dekade 20-29, 30-39, 40-49 i 50-59 jasno se može uočiti da su ispitanici značajno više evocirali sećanja koja su se ticala formiranja porodice, brige o budućim generacijama i profesionalne ostvarenosti. Dakle, u ovim dekadama, najdostupnije memorije su se ticale razvojnih zadataka stadijuma generativnosti. U kontekstu prethodnog razmatranja, ali i s obzirom na prosečnu starost ispitanika, interesantan je rezultat koji pokazuje da su sećanja klasifikovana kao pitanja integriteta i životnog smisla počela da se javljaju u poznijim životnim dekadama, počevši od 40-49 dekade. Relativni mali broj uspomena je bio klasifikovan kao sećanja završenog životnog ciklusa jer je mali broj ispitanika $(\mathrm{N}=5)$ u našem uzorku imao $80+$ godina. Dakle, generalno, rezultati potkrepljuju našu pretpostavku da najdostupnija autobiografska sećanja evocirana u okviru tačno određenih životnih dekada, putem razvojno relevantnih zadataka osobe, korespondiraju sa Eriksonovim stadijumima psihosocijalnog razvoja.

Tabela 1 pokazuje da su ispitivani stadijumi zasićeni različitim brojem sećanja, pri čemu stadijum generativnosti sadrži najveću proporciju evociranih sećanja (Kolmogorov-Smirnov $Z=11.22, p<.001$ ). Iz Figure 1 koja prikazuje distribucije memorija tokom životnih dekada klasifikovanih prema Eriksonovim stadijumima može se videti da se razvojni zadaci stadijuma generativnosti protežu kroz celo srednje životno doba. Nasuprot njemu, distribucije memorije vezane za stadijume detinjstva, identiteta i donekle intimnosti su imale jasno istaknut šiljak sugerišući da su razvojni zadaci ovih stadijuma u većoj meri vezane za određene životne dekade. 


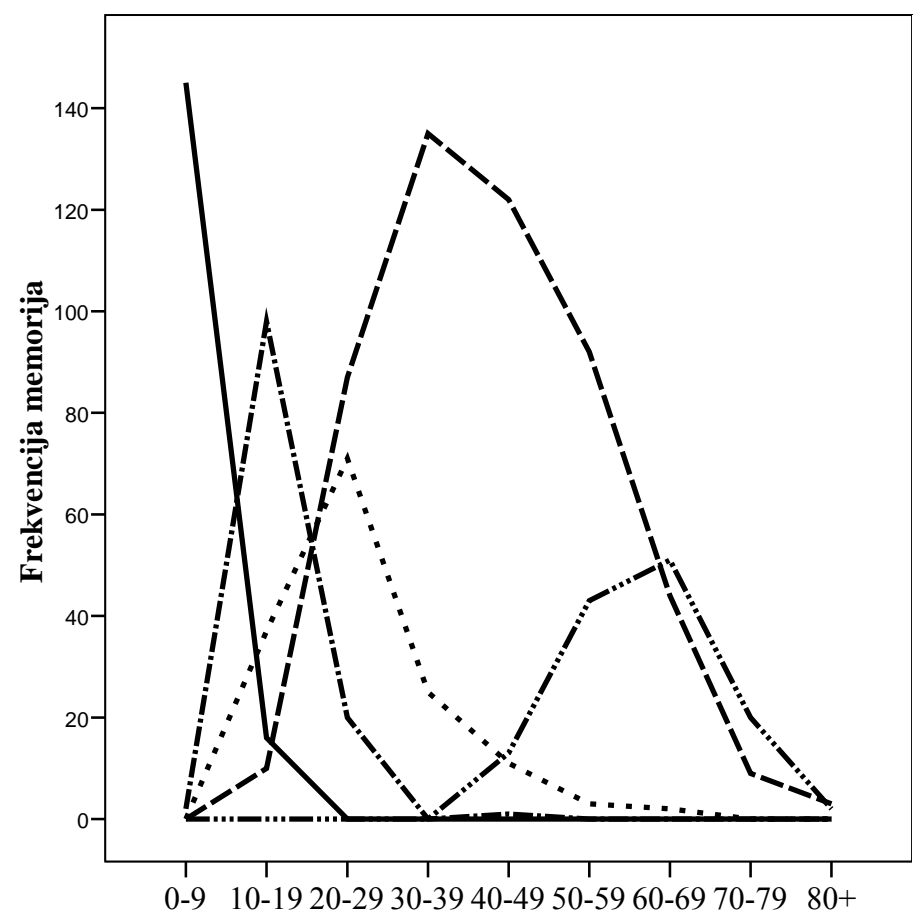

Eriksonovi stadijumi

- detinjstvo

--- identitet

... intimnost

- - generativnost

$-\cdots$ integritet

Dekada

Grafik 1. Frekvencija memorija po dekadama s obzirom na Eriksonove stadijume ${ }^{2}$

Što se emocionalnog tona najpristupačnijih autobiografskih memorija tiče, podaci iz tabele 2 pokazuju da je najveći broj evociranih sećanja bio pozitivno emocionalno obojen (40\%), dok su negativne (26\%) i ambivalentne memorije (21\%) bile zastupljene u manjoj meri $\left(\chi^{2}(24)=54,10, \mathrm{p}<.001\right.$; Cramer's $\mathrm{V}=$ $0,12, p<.001)$. Neutralne memorije su bile zastupljene $u$ najmanjoj meri (13\%). Dakle, očekivanje o prisutnosti tendencije evociranja pozitivnih afekata i iskustava kod starijih osoba je potkrepljeno pri čemu su dobijeni procenti komparabilni sa rezultatima prethodnih studija.

Između različitih dekada nisu postojale razlike u distribuciji pozitivnih sećanja (Friedmanov test, $X_{(6, \mathrm{~N}=46)}^{2}=7.52$, n.z.). Iako je Friedmanov test sugerisao da postoji razlika u distribuciji negativnih memorija između dekada (Friedmanov

\footnotetext{
${ }^{2}$ Distribucija sećanja iz stadijuma završen životni ciklus nije prikazana zbog relativno malog broja ispitanika koji su imali $80+$ godina. Takođe, i u sledećoj analizi, analizi korespodencije, ova sećanja nisu razmatrana usled istog razloga.
} 
test, $\left.X^{2}(6, \mathrm{~N}=46)=12.47, p<.05\right)$, serija post-hoc testova sa Bonferonijevom korekcijom alfa nivoa (Wilcoxon-Sign Ranks test) nije ukazala da postoje razlike $u$ medijani distribucija negativnih memorija između parova dekada.

Tabela 2. Emocionalni ton autobiografskih memorija prema životnim dekadama

\begin{tabular}{llllll}
\hline & \multicolumn{5}{c}{ Emocionalniton } \\
\cline { 2 - 6 } Životne dekade & Pozitivan & $\begin{array}{l}\text { Negati- } \\
\text { van }\end{array}$ & $\begin{array}{l}\text { Ambivalen- } \\
\tan \end{array}$ & Neutralan & Ukupno \\
\cline { 2 - 6 } & 65 & 53 & 32 & 36 & 186 \\
$10-19$ & 74 & 54 & 44 & 21 & 193 \\
$20-29$ & 101 & 32 & 44 & 17 & 194 \\
$30-39$ & 81 & 30 & 41 & 28 & 180 \\
$40-49$ & 66 & 54 & 35 & 22 & 177 \\
$50-59$ & 58 & 53 & 37 & 20 & 168 \\
$60-69$ & 46 & 39 & 27 & 11 & 123 \\
$70-79$ & 10 & 11 & 7 & 8 & 36 \\
$80+$ & 4 & 0 & 1 & 3 & 8 \\
Ukupno & 505 & 326 & 268 & 166 & 1265 \\
\hline
\end{tabular}

Preostale analize su se ticale provere efekta reminiscencije. Distribucija pozitivnih sećanja tokom životnih dekada se statistički značajno razlikovala od uniformne distribucije (Kolmogorov-Smirnov $Z=5.99, p<.001$ ) pri čemu je najveći broj pozitivnih memorija bio vezan za uzrast između 20 i 40 godine. Iako se distribucija negativnih najpristupačnijih sećanja takođe razlikovala $\mathrm{u}$ odnosu na uniformnu distribuciju (Kolmogorov-Smirnov $Z=3.35, p<.001$ ), iz Tabele 2 se može videti da je u periodu između 20 i 40 godine broj negativnih sećanja težio da bude manji u odnosu na ostale dekade.

Prethodne analize su posmatrale distribucije sećanja različitog emocionalnog tona nezavisno jedne od druge. Kako bi istovremeno razmatrali distribucije različitog emocionalnog tona urađena je analiza korespondencije. Dobijena vrednost hi-kvadrata je sugerisala da su ove dve varijable međusobno povezane $\left(\chi_{(21)}^{2}=47,95, p<.01\right)$, pri čemu su prve dve izolovane dimenzije objasnile $98 \%$ od ukupne inercije (tj. hi-kvadrat/1257). Figura 2 prikazuje rezultate analize. Može se videti da su se dekade ranog zrelog doba (tj. 20-29 i 30-39) razlikovale od 0-9 dekade i kasnijih životnih dekada po relativno većoj proporciju pozitivnih memoriju u poređenju sa negativnim memorijama. 


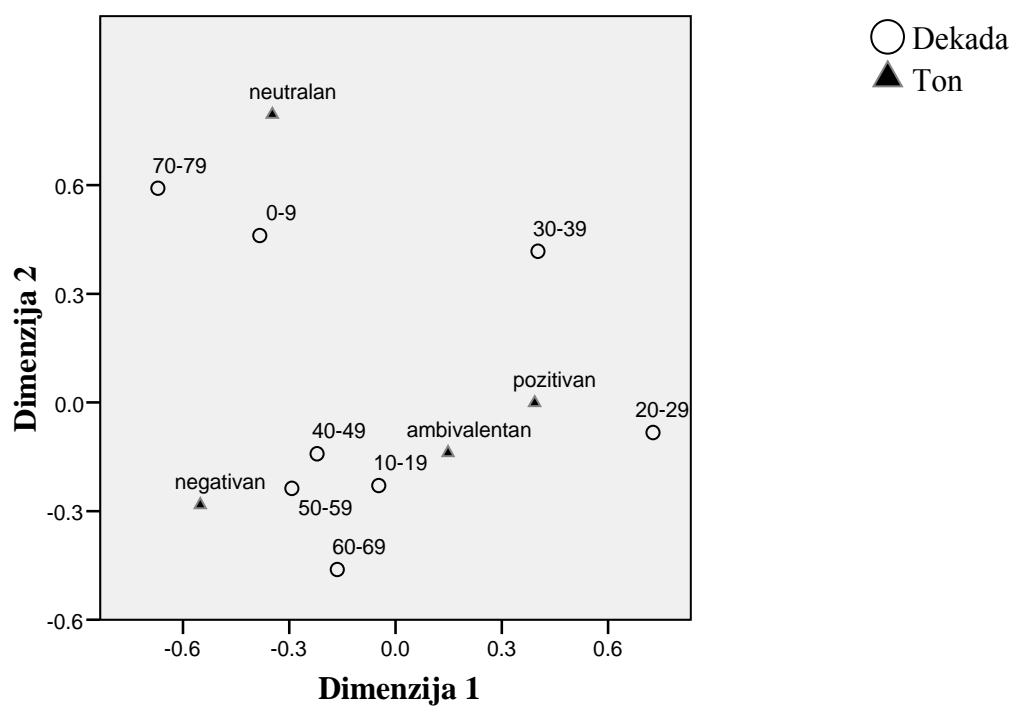

Figura 2. Analiza korespondencije: Emocionalni ton memorija i životne dekade

\section{Diskusija}

Istraživanje je koncipirano u skladu sa idejom da postoje bliske veze između selfa i memorije pri čemu se pošlo od pretpostavke da trenutno aktuelni razvojni zadaci selfa služe kao organizator memorija određujući stepen dostupnosti autobiografskih memorija (Rathbone et al., 2008). Eriksonova teorija psihosocijalnog razvoja nam je poslužila kao teorijski okvir za razumevanja razvojnih zadataka tokom životnog ciklusa osobe.

Rezultati dobijeni ovim istraživanjem govore $u$ prilog početne pretpostavke da sećanja evocirana u okviru tačno određenih životnih dekada korespondiraju sa Eriksonovim stadijumima psihosocijalnog razvoja, čime sugerišu da self kroz konfiguraciju određenih prošlih, za osobu visoko relevantnih ciljeva, organizuje i klastere visoko dostupnih self-determinišućih memorija. Dakle, i na našem govornom i kulturološkom području je pokazano da su visoko dos- 
tupna autobiografska sećanja ona koja su kodirana tokom perioda kada je osoba bila angažovana oko realizovanja važnih životnih zadata, te su pri evociranju najpristupačnija upravo ona koja odražavaju visoki nivo relevantnosti za self (Conway \& Holmes, 2004).

U okviru najvećeg broja stadijuma, ispitanici su se, u skladu sa aktuelnim razvojnim zadacima istog, dominantno prisećali događaja tog konkretnog perioda, čime su maksimizirali broj sećanja za taj određeni psihosocijalni stadijum. Generativnost je jedan od najdužih životnih stadijuma te se pretpostavilo da će se najveći broj klasifikovanih memorija iz životnih dekada srednjeg odraslog doba odnositi na teme kao što su uspostavljanje porodice, briga o budućim generacijama i izgradnja karijere. Sa druge strane, za sećanja iz ostalih stadijuma se pretpostavilo da će zbog prirode njihovih razvojnih zadataka (na primer, uspostavljanje poverenja ili izgradnja identiteta), jasnije korespondirati sa određenim životnim dekadama. Naši rezultati su generalno u skladu sa pretpostavkama. Naime, s obzirom na sadržaj, najveći broj sećanja evociran u razdoblju od 30 do 60 godine se odnosio na razvojne zadatke i životne ciljeve, koji po Eriksonovo teoriji, korespondiraju sa stadijumom generativnosti. Važno je takođe naglasiti da su tridesete, četrdesete i pedesete godine naših ispitanika bile ispunjene izdiferenciranim sećanjima i događajima. Dakle, nasuprot uverenjima pojedinih autora po kojima između četrdesetih i šezdesetih godina nastupa period stabilnosti i rutinskih aktivnosti koji se stapaju u amorfnu masu sećanja, naši podaci sugerišu mnogo izdiferenciranju sliku. Današnjica izgleda da diktira nešto složeniji i svakako ubrzaniji tempo života, koji dodatno komplikuje prilagođavanje tranziciji srednjih godina. Trogeneracijski sistem životnog toka porodice, odnosno potreba za sticanjem i obezbeđivanjem egzistencijalnih sredstava, briga o deci koja sve kasnije napuštaju roditeljske domove i izgrađuju samostalan život, kao i briga o starima čiji je životni vek posredstvom naučnih dostignuća značajno produžen, doprinose dužem zadržavanju pojedinaca u stadijumu generativnosti, a time i bogatijem spektru šarenolikih sećanja koja sadrže karakteristike upravo ovog stadijuma.

Zbog relativno malog broja vrlo starih ispitanika koji su mogli da evociraju sećanja iz poznijih životnih godina, nismo mogli da nedvosmisleno utvrdimo postojanje devetog životnog stadijuma o kome nam govore posthumni Eriksonovi spisi. Međutim, rezultat da je početak javljanja sećanja klasifikovanih kao završen životni ciklus bio vezan za kasniju životnu dekadu (50-59) u odnosu na integrativna sećanja sugeriše mogućnost postojanja kvalitativno drugačijeg životnog stadijuma vezanog za pozne godine. Nova istraživanja bi trebalo da dalje validiraju ovu pretpostavku. 
Što se emocionalnog tona autobiografskih sećanja tiče, dobijeni podaci, pri čemu je $40 \%$ sećanja okarakterisano kao pozitivno a $26 \%$ kao negativno, repliciraju nalaze drugih istraživača. Drugim rečima, uklapaju se u obrazac identifikovan prethodnim istraživanjima i potkrepljuju tvrđenje da ljudi generalno teže da događaje u autobiografskoj memoriji percipiraju kao pozitivne i prijatne (Walker et al., 2003). Ovakav obrazac, čini se, da je svojstven svakoj životnoj dekadi. Dalja istraživanja na našoj populaciji bi trebalo da budu usmerena objašnjenu ovog fenomena pri čemu kao teorijski okvir mogu da posluže različite motivacione teorije. Za istraživanje stare populacije posebno je interesantna Karstensenova teorija socioemocionalnog selektiviteta prema kojoj su starije osobe motivisane da maksimiziraju pozitivan afekat i minimiziraju negativan (Carstensen, Isaacowitz, \& Charles, 1999). S obzirom na to da su naši ispitanici uglavnom bili u stadijumu integriteta koga karakteriše težnja za prihvatanjem sopstvenog života i utvrđivanje smisla istog putem integrisanja proživljenih događaja u svoj životni kontinuum, sasvim je moguća tendencija prisećanja pozitivnih iskustava sa ciljem minimiziranja negativnih, podstaknuta svešću o blizini sopstvene smrti.

Poslednji rezultat koji treba prodiskutovati tiče se efekta reminiscencije tj. tendencije da se odrasle osobe najbolje prisećaju uspomena iz mladog odraslog doba. Naši podaci su u skladu sa novijim saznanjima iz ove oblasti koji sugerišu da je bolje prisećanje vezano za pozitivna sećanja a da negativna i traumatska sećanja ne doprinose efektu reminiscencije. U poređenju sa prethodnim studijama koje su ispitivale efekat korišćenjem metodologije koja zahteva strategijsku pretragu informacija u dugotrajnoj memoriji (na primer, davanje asocijacija na određenu reč, opis najživopisnijih uspomena, opis najvažnijih uspomena ili uspomena koje čine životnu priču), naše istraživanje pokazuje da je efekat prisutan i među najdostupnijim pozitivnim sećanjima tokom zadatka slobodnog prisećanja unutar životnih dekada. Ukoliko prihvatimo pretpostavku da su sećanja dobijena na ovaj način, u stvari, sećanja koja bitno određuju naš aktuelni ili prošli self, kao što to zagovaraju Convey i Holms (2004) ili Singer i Salovey (1993), naši podaci mogu da se interpretiraju u svetlu Teorije formiranja identiteta. Tokom kasne adolescencije i ranog odraslog doba (20 i 30 godine) po prvi put se formira jasan, stabilan self, i to razvojno dostignuće se manifestuje u jasnom klasteru self-determinišućih uspomena (Gluck \& Bluck, 2007).

U cilju jasnije ocene rezultata ovog istraživanja, bitno je naglasiti i njegove brojne nedostatke. U pitanju je retrospektivno istraživanje koje nije u stanju da poredi izveštaje ispitanika o uspomenama i njihovom emocionalnom tonu sa emocionalnim tonom kada su se događaji i zbili. Nalazi su se u velikoj meri 
oslanjali na saglasnosti dva kodera. Iako su koderi postigli izuzetan stepen slaganja prilikom klasifikacije sećanja po stadijumima i emocionalnom tonu, buduća istraživanja bi trebalo da se zasnivaju na percepcijama i procenama samih ispitanika. Nadalje, informacija koja nije bila dostupna odnosila se na trenutno emocionalno i kognitivno stanje ispitanika u momentu istraživanja. Ostaje nepoznato u kojoj meri rezultati reflektuju doprinos ovih važnih varijabli. U cilju proučavanja poslednje životne faze, završenog životnog ciklusa, buduća istraživanja bi trebalo da uključe veći broj osoba iznad 80 godina. Nemogućnost da se ispitaju sećanja iz različitih stadijuma iz perioda detinjstva zasebno onemogućilo je testiranja Eriksonove teorije u celini.

\section{Zaključak}

Sa aspekta postavljenih ciljeva na početku rada, obrađena autobiografska sećanja pružaju jasan uvid i slikovito dočaravaju izrazitu kompleksnost životnog iskustva svakog pojedinca. Životni ciljevi postavljeni na bazi definisanja svrhe sopstvenog postojanja, odnosno definisanja "misije" svog života, čije se ispunjenje realizuje duži niz godina, a čije posledice traju doživotno, sasvim sigurno predstavljaju neku vrstu organizatora autobiografskih sećanja. Posebno je važno da se dalja istraživanja usmere na razumevanje razvojne dinamike kod vrlo starih osoba kao i njihovih karakterističnih strategija regulacija afekta. Determinisanjem karakterističnih zadataka ovog poslednjeg stadijuma otvara se područje implikacija o značaju sticanja nade i poverenja, izbegavanja predavanja sudbini, ali i okretanja ka transcendentalnoj životnoj sferi starih osoba. Istraživanja ovog tipa mogla bi da doprinesu smanjenju neosnovanih generalizacija i eliminisanju duboko ukorenjenih negativnih stereotipa o procesu starenja, starim ljudima i starosti kao životnom dobu, u cilju unapređenja kvaliteta života i sistema podrške starim osobama u Srbiji. 


\section{Literatura}

Bernsten, D., \& Rubin, D. C. (2002). Emotionally charged autobiographical memories across life span. The recall of happy, sad, traumatic, and involuntary memories. Psychology \& Aging, 17, 636-652.

Brewer, W. F. (1986). What is autobiographical memory? In D. Rubin (Ed.), Autobiographical memory (pp. 25-49). Cambridge: Cambridge University Press.

Brown, C. \& Lowis, M. (2003). Psychosocial development in the elderly: An investigation into Erikson's ninth stage. Journal of Aging Studies. 17, 415426.

Carstensen, L. L. (1991). Socioemotional selectivity theory: Social activity in life-span context. Annual Review of Gerontology and Geriatrics, 11, 195217.

Carstensen, L. L., Isaacowitz, D. M., \& Charles, S. T. (1999). Taking time seriously: A theory of socioemotional selectivity. American Psychologist, $54,165-181$.

Charles, S. T., Mather, M., \& Carstensen, L. L. (2003). Aging and emotional memory: The forgettable nature of negative images for older adults. Journal of Experimental Psychology: General, 132, 310-324.

Conway, M. A., \& Haque, S. (1999). Overshadowing the reminiscence bump: Memories of a struggle for independence. Journal of Adult Development, 6, 35-44.

Conway, M. A., \& Holmes, A. (2004). Psychosocial stages and the accessibility of autobiographical memories across the life cycle. Journal of Personality, 72. 461-480.

Conway, M. A., \& Pleydell-Pearce, C. W. (2000). The construction of autobiographical memory in the self-memory system. Psychological Review, 107, 261-288.

Gluck, J., \& Bluck, S. (2007). Looking back across the life-span: A life-story account of the reminiscence bump. Memory and Cognition, 35, 19281939.

Jerković, I., i Zotović, M. (2005). Uvod u razvojnu psihologiju. Beograd: Centar za primenjenu psihologiju. 
Kennedy, Q., Mather, M., \& Carstensen, L. L. (2004). The role of motivation in the age-related positivity effect in autobiographical memory. Psychological Science, 15, 208-214.

Kostić, A. (2006). Kognitivna psihologija. Beograd: Zavod za udžbenike i nastavna sredstva.

Levine, L. J., \& Bluck, S. (1997). Experienced and remembered emotional intensity in older adults. Psychology and Aging, 12, 514-523.

Martin, P., \& Smyer, M. A. (1990). The experience of micro and macro events: A life-span analysis. Research on Aging, 12, 294-310.

Mather, M., \& Carstensen, L. L. (2003). Aging and attentional biases for emotional faces. Psychological Science, 14, 409-415.

Rathbone, C. J., Moulin, C. J., Conway, M. A. (2008). Self-centered memories: The reminiscence bump and the self. Memory and Cognition, 36, 14031414.

Seidlitz, L., Wyer, R. S., \& Diener, E. (1997). Cognitive correlates of subjective well-being: The processing of valenced life-events by happy and unhappy persons. Journal of Research in Personality, 31, 240-256.

Thompson, C. P., Skowronski, J. J., Larsen, S., \& Betz, A. (1996). Autobiographical memory: Remembering what and remembering when. New York: Erlbaum.

Tornstam, L. (1992). The quo vadis of gerontology: On the scientific paradigm of gerontology.The Gerontologist, 32, 318-326.

Piolino, P., Desgranges, B., Benali, K. \& Eustache, F. (2002). Episodic and semantic remote autobiographical memory in aging. Memory, 10, 239-257.

Rubin, D.C., Rahhal, T.A., \& Poon, L.W. (1998). Things learned in early adulthood are remembered best. Memory \& Cognition, 26, 3-19.

Schroots, J. J. F., Van Dijkum, C. \& Assink, M. H. J. (2004). Autobiographical memory from a lifespan perspective. International Journal of Aging and Human Development, 58, 69-85.

Singer, J. A., \& Salovey, P. (1993). The remembered self: Emotion and memory in personality. New York: Free Press.

Wagenaar, W. A., \& Groeneweg, J. (1990). The memory of concentration camp survivors. Applied Cognitive Psychology, 4, 77-87. 
Walker, W. R., Skowronski, J. J., \& Thompson, C. P. (2003). Life is pleasantand memory helps to keep it that way. Review of General Psychology, 1, 203-210.

Walker, W. R., Skowronski, J. J.,Gibbons, J. A., Vogl, R. J., \& Thompson, C. P. (2003). On the emotions that accompany autobiographical memories: Dysphoria disrupts the fading affect bias. Cognition \& Emotion, 17,703724.

Walker, W. R., Vogl, R. J., \& Thompson, C. P., (1997). Autobiographical memory: Unpleasantness fades faster than pleasantness over time. Applied Cognitive Psychology, 11, 399-413. 


\section{Abstract \\ AUTOBIOGRAPHICAL MEMORY AND ERIKSON'S STAGES OF PSYCHOSOCIAL DEVELOPMENT}

Ljiljana Mihić, Kristina Krstić, and Ivana Ignjatović

This research was conducted in order to explore: 1) autobiographical memories in older adults guided by Erikson's psychosocial theory, 2) emotional tone of autobiographical memories, and 3) the reminiscence bump. The sample consisted of 65 subjects with an average age of 69 , who resided in different parts of the Republic of Serbia. Via interviews, they evoked 1265 personal memories. The data were analyzed using descriptive statistics, nonparametric tests, and correspondence analysis. The findings were supportive of the following hypotheses: 1) the most accessible autobiographical memories evoked within particular life decades corresponded to Erikson's stages of psychosocial development, 2) the majority of autobiographical memories were positively valenced, and 3) the reminiscence bump was evident only in positively valenced autobiographical memories but not in negatively valenced memories. The results were discussed in the light of the Self-Memory System Theory.

Keywords: autobiographical memory, developmental stages, emotional tone, reminiscence bump, Erikson

Primljeno: 1.12.2009; prihvaćeno za štampu: 17.12.2009. 